\title{
La Píldora del día después y el Fallo del Tribunal Constitucional
}

\author{
M. FRANCISCA UGARTE P. ${ }^{1}$ \\ 1. Pediatra, Endocrinóloga Infantil. \\ Unidad de Endocrinología, Hospital Exequiel González Cortés. \\ Servicio de Pediatría, Unidad de Endocrinología Pediátrica y Unidad de Atención Integral del Adolescente, Clínica Alemana \\ de Santiago.
}

\section{Introducción}

El reciente Fallo del Tribunal Constitucional que resolvió la inconstitucionalidad de la Píldora del Día Después y por tanto la prohibición de su distribución, no ha dejado indiferente a quienes hemos tratado de tener una opinión fundada en la evidencia científica, en nuestra legislación vigente y en los valores que se deben considerar para su análisis.

El fallo se encuentra disponible en su versión completa (277 páginas) vía electrónica ${ }^{1} \mathrm{y}$ debiera ser lectura obligatoria para quienes están involucrados en cuanto participan en las decisiones de políticas nacionales, institucionales y/o quienes en su práctica profesional deben resolver la indicación de la Píldora del Día después.

El Fallo contiene los fundamentos del requerimiento presentado por los miembros de la Cámara de Diputados, las observaciones del Ejecutivo y del Contralor de la República, las consideraciones del Tribunal Constitucional con los fundamentos de los votos de mayoría y de disidencia, así como la opinión de los expertos consultados y la bibliografía referida por cada uno de ellos.

El objetivo de esta Editorial es, a la luz de literatura expuesta por los expertos y aquella disponible en pubmed, comentar el estado ac- tual de este conocimiento, y resumir en forma breve las consideraciones hechas por los jueces cuyo voto de mayoría determinó la inconstitucionalidad de la píldora del día después.

Como médico, hago notar mis falencias en el área del Derecho, sin embargo, he realizado un esfuerzo real por comprender las consideraciones que tuvieron los jueces. Por otra parte, en busca de una adecuada interpretación del fallo, he solicitado y agradezco en todo lo que vale la asesoría del Abogado y Profesor de Derecho Constitucional, Sr. Julio Lavín Valdés.

\section{Antecedentes generales}

El día cinco de marzo de dos mil siete, treinta y seis Diputados en ejercicio y que representan más de la cuarta parte de la Honorable Cámara de Diputados, formularon un requerimiento ante el Tribunal Constitucional para que declarara la inconstitucionalidad de "todo o parte" del Decreto Supremo Reglamentario $\mathrm{N}^{\mathrm{o}} 48$, del Ministerio de Salud, publicado en el Diario Oficial, en su edición del día tres de febrero del año dos mil siete, que aprueba las "Normas Nacionales sobre Regulación de la Fertilidad". Quince días después, el veinte de marzo de dos mil siete, el tribunal no admitió a tramitación el requerimiento por considerar 
que éste "carece de la claridad y precisión suficientes para que el Tribunal pueda entrar a conocer del asunto".

El día 24 de marzo de 2007, el grupo de diputados presenta un nuevo requerimiento, más específico, que solicita en concreto al Tribunal Constitucional declare la inconstitucionalidad del Decreto Supremo Reglamentario $\mathrm{N}^{\circ} 48$, del Ministerio de Salud, publicado en el Diario Oficial en su edición del día tres de febrero del año dos mil siete, que aprobó las "Normas Nacionales sobre Regulación de la Fertilidad"; en 3 puntos específicos: a) Sección C: Tecnología Anticonceptiva": Punto 3.3. "Anticoncepción hormonal de emergencia" Párrafo 4 "Anticoncepción no hormonal", Punto 4.1.1. "Dispositivos intrauterinos" b) Sección D: Anticoncepción en Población Específica" en cuanto la norma que regula "la consejería a adolescentes que se da en el marco de la confidencialidad, esto es, sin el consentimiento ni conocimiento de los padres", lo cual, a juicio de los peticionarios, sería contrario a lo dispuesto en el inciso tercero del $\mathrm{N}^{\mathrm{o}} 10$ del artículo 19 de la Carta Fundamental que vulnera el derecho y deber preferente de los padres a educar a sus hijos, reconocido en la norma constitucional citada en el numeral 2 precedente.

Finalmente, el día 28 de abril de 2008, el Tribunal Constitucional comunica el fallo que resuelve la inconstitucionalidad de la Píldora del Día Después.

\section{Consideraciones del Tribunal constitucional}

\section{Efectos de la Píldora del Día Después}

Existe a nivel científico consenso en que el uso de Levonorgestrel (LNG) produce diferentes efectos según el momento del ciclo en que se administre.

Los trabajos clásicos de Wilcox y cols ${ }^{2}$, que estudiaron la probabilidad de embarazo de acuerdo al momento de ovulación y el tiempo de la relación sexual en relación a esta, demuestran que el riesgo es cercano al $28 \%, 30 \%$ y $32 \%$ si la relación sexual (RS) ocurre en los días $-2,-1$ y 0 , respectivamente y los días -3 y 1 después de la ovulación el riesgo es cercano al $0 \%$. Será entonces este el período crítico que diferencia- rá si levonorgestrel (LNG) en su forma pura (0,75 mg, 2 dosis separadas por $12 \mathrm{~h}$ ) o combinada (Etinilestradiol $100 \mathrm{ug}+\mathrm{LNG} \mathrm{0,5} \mathrm{mg,} 2$ dosis separadas por $12 \mathrm{~h}$ ) actúa sólo inhibiendo o retrasando la ovulación, o bien una vez ocurrida la fecundación si actúa alterando el desarrollo y posterior implantación del embrión.

Los efectos de levonorgestrel que han despertado polémica, se refieren a su uso en el periodo periovulatorio, donde existen resultados controvertidos.

\section{a) Efectos sobre la ovulación:}

La mayoría de los autores concuerdan en que cuando se utiliza en la primera mitad del ciclo retrasa o impide la ovulación ${ }^{3-5}$. Sin embargo, publicaciones recientes en mujeres que solicitaron anticoncepción de emergencia (ACE), demuestran que cuando el folículo dominante tiene $18 \mathrm{~mm}$ o más, o el peak de LH ya se ha iniciado (24 a $36 \mathrm{hr}$ antes de la ovulación), $42 \%$ y $79 \%$ de las pacientes ovula, respectivamente, al utilizar LNG sólo ${ }^{6}$; si se usa LNG-EE (Juzpe) $100 \%$ ovulan si tenían folículo dominante de $18 \mathrm{~mm}$ o más ${ }^{7}$. Los estudios de Massai y Croxato (2007), encuentran un porcentaje global de ovulación de $50 \%$ en usurarias de LNG sólo ${ }^{6}$.

\section{b) Efectos sobre los espermios:}

Yeung ${ }^{8}$ demostró que LNG sólo altera la función de los espermios en dosis 10 veces la que se alcanzan al utilizar ACE. Considerando que los primeros espermios capacitados se encuentran en el tercio distal de la trompa alrededor de las 6 horas de una relación sexual, el efecto de LNG sobre los espermios no contribuiría al efecto anticonceptivo de la ACE.

\section{c) Efectos sobre el moco cervical:}

Kesserü ${ }^{9}$, demostró que con dosis de LNG $0,4 \mathrm{mg}$ (dosis menor que la utilizada en ACE) disminuyen significativamente la penetración de espermios a cuello del útero a las $9 \mathrm{~h}$ y la recuperación de éstos desde cavidad uterina, desde las $7 \mathrm{~h}$. También se han demostrado alteraciones en la calidad del moco cervical y la penetración espermática con implante de $\mathrm{LNG}^{10}$ a las 24 horas de puestos. Así la utilización de LNG post coital disminuiría el paso de espermios 
sólo provenientes de relaciones sexuales posteriores y no de la RS que determinó el uso de ACE.

\section{d) Efectos sobre el transporte tubario}

Paltieli $^{11}$, demostró que la progesterona en altas dosis tiene efecto paralizante sobre los cilios del oviducto humano: $50 \%$ parálisis con 2 ug/L. Con LNG 0,75 mg se alcanzan 9,4 ug/L $\mathrm{L}^{12}$ y si consideramos que la acción progestínica de LNG es 18 veces mayor que la de progesterona, uno de sus efectos probables es alterar el transporte del embrión por la trompa. Por otra parte, Sheffer-Mimouni ${ }^{13}$ reportó 3 casos de embarazo tubario en mujeres sin factores de riesgo conocidos para esta condición, posterior al uso de LNG.

\section{e) Efectos sobre el endometrio}

Los hallazgos histológicos de Ling y cols $1^{1,14}$, demuestran asincronía en el desarrollo del estroma y del epitelio glandular, así como un leve avance de la maduración endometrial.

Los estudios de microscopía electrónica de Ugocsai $\mathrm{G}^{15}$, con dosis de LNG $(3,75 \mathrm{mg}$ el día 16 y $0,75 \mathrm{mg}$ el día 17 del ciclo) revelan marcada reestructuración del endometrio, con reducción del número de células ciliadas, desaparición de los cilios en la fase proliferativa y periovulatoria, así como desaparición de los pinopodios en la fase secretoria.

Otros autores han descrito alteraciones en el proceso de adherencia. Así Raymond y cols ${ }^{16}$, describen que con LNG-E el día del peak de LH y a las $12 \mathrm{~h}$, determina cambios significativos en disminución de expresión de MUC-1 endometrial, aumento de receptores de estrógenos endometriales, disminución de la concentración de estrógenos séricos en la fase lútea, disminución del grosor del endometrio y mayor proporción de vacuolas supranucleares glandulares. Por otra parte, $\mathrm{Wu}$ y cols ${ }^{17}$, utilizando histoquímica, describe disminución de la expresión de las subunidades $\alpha 1$ y $\alpha 4$ integrinas. MUC-1 es una de las primeras proteinas de adherencia y las subunidades de integrinas también participan en este proceso.

Respecto de la capacidad secretoria del endometrio, está descrito una prolongada e intensa alcalinización del liquido uterino ${ }^{9}$ (los embrio- nes en fertilización in vitro no sobreviven a $\mathrm{pH}$ 8 o más) y despararición de la proteina glicodelina $\mathrm{A}^{18}$ (fundamental para evitar la respuesta inmune contra el embrión).

\section{f) Efectos sobre el cuerpo lúteo}

Respecto de los efectos de LNG sobre la función del cuerpo lúteo, se ha descrito acortamiento de la fase lútea probablemente secundario a disminución del peak de $\mathrm{LH}^{19}$; lo que ya había sido observado por otros autores ${ }^{20}$.

En resumen, considerando la bibliografía expuesta si se administra LNG 48 h después de una relación sexual no protegida, que ocurrió 12 horas antes de la ovulación, y una segunda dosis 12 horas después, podemos esperar que: se ovulará normalmente ( $36 \mathrm{~h}$ antes de recibir LNG), los espermios capacitados alcanzarán el tercio distal de la trompa alrededor de las 6 horas de la RS, se producirá la fusión del óvulo con el espermio (concepción), originándose un cigoto. Este iniciará el viaje por la trompa hacia el endometrio e iniciarán las sucesivas divisiones celulares sucesivas, sin embargo el transporte tubario estará posiblemente disminuido (impidiendo que este llegue en etapa de blastocisto a la cavidad endometrial), el líquido endometrial será alcalino (con la posible desvitalización del embrión) y encontrará un líquido uterino desfavorable con disminución de proteínas de adherencia y disminución proteínas de protección inmunológica que requiere el embrión. Si el embrión ha logrado sobrevivir a todo lo anterior, las alteraciones del cuerpo lúteo hacen menos probable una progresión normal del embarazo.

\section{Consideraciones del voto de mayoría}

Las principales consideraciones del voto de mayoría pueden resumirse en los siguientes 9 puntos principales:

1. El derecho a la vida queda asegurado en el Art. $19 \mathrm{~N}^{\mathrm{o}} 1$ de la Constitución -en consonancia con el Art. $3^{\circ}$ de la Declaración Universal de los Derechos Humanos; el Art. 6.1 del Pacto Internacional de Derechos Civiles y Políticos; el Art. $1^{\circ}$ de la Declaración Americana de los Derechos y Deberes del Hombre, y el Art. $4^{\mathrm{o}}$ de la Convención Americana de Derechos 
Humanos -asegura a toda persona, incluyendo al nasciturus - el derecho a mantener la vida y a conservarla frente a los demás hombres.

2. La protección constitucional de la persona a partir del momento de la concepción en Chile se vio plenamente reafirmada al discutirse la reforma al artículo $1^{\circ}$, inciso primero, de la Carta Fundamental, que cambió la expresión "hombres" por "personas" y que se concretó a través de la Ley $\mathrm{N}^{\circ} 19.611,128$ publicada en el Diario Oficial de 16 de junio de 1999. Durante el segundo trámite de esa reforma constitucional, verificado en el Senado, se aprobó dejar constancia que: "El nasciturus, desde la concepción, es persona en el sentido constitucional del término, y por ende es titular del derecho a la vida".

3. Junto con asegurar el derecho a la vida y a la integridad física y psíquica de la persona, nuestra Carta Fundamental ordenó: "la ley protege la vida del que está por nacer".

4. Considerando que, la Constitución impone a los Órganos del Estado respetar y promover los derechos asegurados por la misma Carta Fundamental, así como por los Tratados Internacionales ratificados por Chile y que se encuentren vigentes.

5. Considerando que las posiciones de los médicos que han aportado antecedentes en esta causa, ya sea a favor o en contra de que la "píldora del día después" en su versión de progestina pura de $0,75 \mathrm{mg}$ o en el método combinado o de Yuzpe, son equivalentes en cuanto ambas sustentan, con idéntico vigor y convicción, su particular punto de vista.

No obstante, existe un elemento que a juicio de los sentenciadores neutraliza tal equivalencia y que tiene que ver con el efecto que ha de producirse de acogerse una $\mathrm{u}$ otra posición. Así, si se acoge la tesis de quienes sostienen que sólo existiría un ser humano y, por ende, una persona desde la implantación del embrión en el endometrio, impidiendo las píldoras del día después tal implantación, no habría atentado contra la vida de una "persona". Por el contrario, si se sigue la tesis de quienes sostienen -como además lo entendió nuestro propio Constituyente- que la vida comienza con la concepción, esto es por la unión del óvulo y del espermatozoide, un eventual efecto de las píldoras del día después que impidiese la implantación de un ser vivo -o de una persona- se transformaría en aborto del todo contrario a la protección constitucional de la vida del que está por nacer.

6. De lo expuesto, sólo es posible concluir que la existencia de una norma reglamentaria (Decreto Supremo No 48) que contiene disposiciones que pueden llevar a afectar la protección del derecho a la vida de la persona que está por nacer y que la Constitución buscó cautelar especialmente, la vulnera porque la sola duda razonable, reflejada en las posiciones encontradas de los expertos del mundo de la ciencia, de que la aplicación de esas normas reglamentarias pueda llegar a afectar el derecho a la vida del nasciturus, obliga al juez constitucional a aplicar el principio "favor persona" o "favor homine".

7. En consecuencia, el Tribunal debe concluir que el imperativo de proteger y promover el derecho a la vida, conduce a declarar inconstitucionales las Normas Nacionales sobre Regulación de la fertilidad, que formar parte del D.S. No 48, de 2007: (Acápite 3.3 de la Sección $\mathrm{C}$, por derivación Sección $\mathrm{D}$, Acápite 1).

8. Considerando que la referida declaración tiene efecto erga omnes, que se desprende del inciso tercero del artículo 94 de la Constitución: "El decreto supremo quedará sin efecto de pleno derecho, con el sólo mérito de la sentencia del Tribunal".

9. De lo expuesto anteriormente tanto los órganos del Estado, como toda persona, institución o grupo se encuentran en el imperativo de acatar la decisión del Tribunal Constitucional, por que ha ejercido la tarea que el propio constituyente le ha confiado velar por la supremacía sustantiva y formal de la Carta Fundamental.

Con el raciocinio anterior, el Tribunal Constitucional resolvió acoger el requerimiento únicamente en cuanto se declara que la Sección $\mathrm{C}$, acápite 3.3 "Anticoncepción Hormonal de Emergencia", así como la Sección D., "Anticoncepción en Poblaciones Específicas", v Acápite 1. sólo en la parte que se refiere a la "anticoncepción de emergencia", del D.S. No 48 , de 2007, son inconstitucionales.

Lo que hace, en consecuencia el Tribunal Constitucional, es declarar inconstitucional, en las parte descritas, el Decreto Supremo $N^{\circ} 48$, 
de 2007, en cuanto ordena aconsejar y distribuir la Píldora del Día Después en sus versiones pura o combinada, prohibiendo su distribución, en tanto puede comprometer el derecho a la vida del embrión en sus primeras etapas de desarrollo, la que es reconocida constitucionalmente.

\section{Consideraciones del voto de disidencia}

El voto de minoría se resume en los siguientes puntos:

1. El no reconocimiento de los derechos constitucionales del embrión considerando que el Código Civil, en su Libro I, se refiere a las personas y las clasifica en naturales y jurídicas; que el Título II, define a las personas naturales en su artículo 55, como todo individuo de la especie humana, cualquiera que sea su edad, sexo, estirpe o condición, disponiendo en su artículo 74 que "la existencia legal de toda persona principia al nacer, esto es, al separarse completamente de su madre."

2. Considerar que el aborto referido y sancionado en los artículos 119 del Código Sanitario y el artículo 342 y siguientes del Código Penal, no especifican el momento a partir del cual se comete el delito de aborto, y que a juicio de los disidentes, sólo corresponde a la interrupción de un embarazo consolidado (desde la anidación) e incluso (para alguno de los magistrados) desde su viabilidad.

3. Considerar que el conflicto sometido a la resolución de esta Magistratura no se encuentra regulado por el sistema jurídico, siendo un tema que se desarrolla dentro del marco de la libertad de conciencia y de creencias, no se estaría en presencia de un conflicto de intereses de relevancia jurídica constitucional.

4. Que al considerar el eventual conflicto entre un interés constitucionalmente protegido y otros derechos fundamentales, como los de orden reproductivo y sexual, debe señalarse que la Carta Fundamental no prohíbe el aborto, que los mencionados derechos reproductivos tienen reconocimiento constitucional y, por último, que el interés preponderante -si existiere un conflicto de valores de relevancia constitucional- recae en los derechos fundamentales de la mujer.

5. A juicio de los disidentes, "no es cuestión demostrada en este juicio la cualidad abortiva del fármaco aludido ni tampoco que su utilización pudiera provocar, en grado de certeza, un peligro de la vida del que está por nacer".

6. A juicio de los disidentes no se ha presentado evidencia para afirmar una duda razonable de que los métodos y fármacos que el Decreto Supremo 48 del Ministerio de Salud de 2007 ordena aconsejar y distribuir, sean capaces de interrumpir la vida de un embrión humano. Por tanto, no se puede acoger este requerimiento y, por ende, estos disidentes concluyen que no hay razones para declararlo inconstitucional y que el requerimiento debe rechazarse en todas sus partes.

Es decir, los votos de disidencia consideran que el embrión no es sujeto de derecho y que no hay evidencia certera de que la píldora del día después actúe dañando al embrión.

\section{Comentario}

$\mathrm{Al}$ analizar las consideraciones que tuvieron los jueces con voto de mayoría y de disidencia, queda claro que por primera vez se lleva la discusión a su tema central: reconocer o no la dignidad de ser humano del embrión desde la fecundación hasta la anidación y por ende sus derechos constitucionales. De este reconocimiento es de donde derivarán las distintas posiciones de quienes promueven o no la anticoncepción de emergencia.

¿Podemos disponer de la vida de este ser humano en sus primeras etapas de desarrollo?, ¿tenemos claro que ninguno de nosotros estaríamos vivos y seriamos considerados personas, si no se hubiera protegido nuestra integridad en estas etapas?, siendo el derecho a la vida un derecho superior mayor que el derecho a la propiedad privada, libertad, derechos reproductivos, etc. ¿podemos priorizar los derechos de la madre, políticas de salud pública $u$ otros, por sobre los del embrión?, la no maleficencia, principio básico de la ética médica, ¿no se aplica al ser humano en sus primeras etapas de desarrollo?

Una discusión seria, en una sociedad en pleno siglo XXI, obliga no solo a los miembros del equipo de salud, legisladores e instituciones involucradas, sino sobre todo a cada uno en 
particular a responder estas preguntas, informarse adecuadamente, revisar la literatura y tomar así una posición que le permita actuar consecuentemente.

La discusión desde el punto de vista ontológico, filosófico y ético, es aún mas amplia y sin duda se extenderá a otros campos de la medicina, como ha ocurrido en otros países: el aborto, la eutanasia y la manipulación de embriones.

Personalmente creo que el ser humano existe, como lo señalan los textos clásicos de embriología, desde la constitución del cigoto y como tal tiene la dignidad de cualquier ser humano, independiente de su tamaño, etapa de desarro1lo, capacidad intelectual, de comunicación, de autonomía, etc. Somos el mismo ser humano desde la concepción hasta la muerte y espero que cuando no podamos defender nuestros derechos constitucionales, alguien mantenga una voz que repita que estos derechos derivan de nuestra dignidad de seres humanos y no de nuestras características y/o capacidades.

\section{Agradecimientos}

Agradezco al Abogado Sr. Julio Lavín Valdés, Profesor de Derecho Constitucional, Universidad Católica de Chile y Universidad de los Andes, por su asesoría en los aspectos legales y por la revisión del manuscrito.

\section{Referencias}

1.- http://www.tribunalconstitucional.cl/index.php/sentencias/download/pdf/914

2.- Wilcox AJ, Weinberg CR: Baird Timing of sexual intercourse in relation to ovulation. Effect on the probability of conception, survival of the pregnancy. New Engl J Med 1995; 333: 1517-21.

3.- Ling W, Robichaud A, Sayid I, Wrinxon W, MacLeod $S C$ : Mode of action of dl-Norgestrel and ethyniylestradoil combination in postcoital contraception. Fertil Steril 1979; 32: 297-302.

4.- Croxatto $H$, Brache V, Pavéz $M$, et al: Pituitry-ovarian function following the standard levonorgestrel emergency contraception dose or a single $0,75 \mathrm{mg}$ dose given on the days preceding ovulation. Contraception, 2004; 70: 442-50

5.- Marions L, Cekan SZ, Bygdeman M, GemzellDanielsson K: Effect of emergency contraception with levonorgestrel or mifepristone on ovarian function. Contraception 69 (2004) 373-7.

6.- Massai MR, Forcelledo ML, Brache V, Tejada AS,
Salvatierra AM, Reyes $M V$, Alvarez F, Faúndes A, Croxatto HB: Does meloxicam increase the incidence of anovulation induced by single administration of levonorgestrel in emergency contraception? A pilot study. Hum Reprod. 2007; 22 (2): 434-9.

7.- Croxatto H, Fuentealba B, Brache $V$, et al: Effect of Yuzpe regimen, given during the follicular phase, on ovarian function. Contraception, 2002; 65: 121-8.

8.- Yeung WS, Chiu PC, Wang CH, Yao YQ, Ho PC: The effects of levonorgestrel on various sperm functions. Contraception 2002, 66: 453-7.

9.- Kesserü E, Garmendia F, Westphal N, Parada J: The hormonal and peripheral effects od d-norgestrel in postcoital contraception. Contraception 1974; 10: 411-24.

10.- Dunson T, Blumenthal P, Álvarez F, et al: Timing of onset of contraceptive effectiveness in Norplant implant. Part I. Changes in cervical mucus. Fertil Steril 1998, 69: 258-66.

11.- Paltieli Y, Eibschitz I, Ziskind G, et al: High progesterone levels and ciliary dysfunction-A possible cause of ectopic pregnancy. J Assis Reprod Genet. 2000; 17: 103-6.

12.- Johansson E, Brache V, Alvarez F, et al: Pharmacokinetic study of different dosing regimens of levonorgestrel for emergency contraception in healthy women. Human Reprod 2002, 17: 1472-6.

13.- Sheffer-Mimouni G, Pauzner D, Maslovitch S, Lessing J, Gamzu R: Contraception 2003; 67: 267-9.

14.- Ling W, Wrixon, Acorn Tanya, Wilson E, Collins J: Mode of action of dl-norgestrel and ethinylestradiol combination in postcoital contraception. III effect of preovulatory administration following tha luteinizing hormone surge on ovarian steroidogenesis. Fertil Steril 1983, 40: 631-6.

15.- Ugocsai G, Rozsa M, Ugocsai P: Scanning electron microscopic (SEM) changes of the endometrium in women taking high doses of levonorgestrel as emergency postcoital contraception. Contraception 2002; 66: 433-7.

16.- Raymond EG, Lovely LP, Chen-Mok M, Seppälä M, Kurman RJ, Lessey BA: Effect of the Yuzpe regimen of emergency contraception on markers of endometrial receptivity. Hum Reprod 2000; 15: 2351-5.

17.- Wu J, Chen $J, X u R$, et al: Efffects of mifepristone and levonorgestrel on the human endometrium during periimplantation. En Chander PP, Van Look PFA Eds. Sexual and reproductive health. Recent advance, future directions. New Delhi, New Age International Publishers, 2001, pag 143-8.

18.- Young D, Wiehle R, Joshi S, Pointdexter A: Emergency contraception alters progesterone-associated endometrial protein in serum and uterine luminal fluid. Obstet Gynecol 1994; 84; 266-71.

19.- Hapanga D, Glasier A, Baird D: The effect of periovulatory administration of levonorgestrel on menstrual cycle. Contraception 2001; 63: 123-9.

20.- Swahn ML, Westlund P, Johannisson E, Bygdeman M: Effect of postcoital contraceptive methods on the endometrium and menstrual cycle. Acta Obst Gynecol Scand 1996; 75: 738-44. 